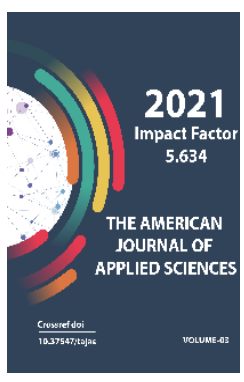

Copyright: Original content from this work may be used under the terms of the creative commons attributes 4.0 licence.

\section{Use Of Experience Gained In The Process Of Teaching Chemistry}

\author{
Akhmadzhon Mirzaevich Jumanov \\ Associate Professor, Department Of Chemistry, Kokand State Pedagogical Institute Named \\ After Mukimiy, Uzbekistan \\ Gulsinoy Mamajonovna Raxmatullaeva \\ Senior Lecturer, Department Of Chemistry, Kokand State Pedagogical Institute Named After \\ Mukimiy, Uzbekistan \\ Gulchexra Salovatovna Meliboeva \\ Senior Lecturer, Department Of Chemistry, Kokand State Pedagogical Institute Named After \\ Mukimiy, Uzbekistan
}

\title{
ABSTRACT
}

This article describes improved experiments on factors influencing the rate of chemical reaction from general chemistry in continuous learning: catalyst and temperature, reagent surface area, dependence on reagent concentration.

\section{KEYWORDS}

Experimental techniques and methods, reaction rate, factors affecting the reaction rate, catalyst, temperature, pressure, surface area ofa substance, concentration of substances, reaction conditions, an increase in the reaction rate.

\section{INTRODUCTION}

In accordance with the Resolution of the President of the Republic of Uzbekistan Sh.M. Mirziyoyev dated August 12, 2020 No. PP-4805 "On measures to improve the quality of continuing education and scientific efficiency in chemistry and biology" Chemistry in higher and secondary schools. Special and general secondary education requires further 
improvement in the teaching of natural sciences.

The role and significance of chemical experiments in the formation of students' practical competencies on the basis of lifelong education are incomparable. One of the urgent tasks of modern chemical education is to further improve the conduct of experiments on the "chemical reaction", which is important for science and the field of chemistry.

Much attention is paid to the experience and skills that students need to acquire in the programs of chemical sciences of higher, specialized secondary and general secondary education, as well as in state educational standards [1; p.33].

It is known that experimental techniques and methods used in the study of chemistry are widely described in the literature [3;p. 34-35].

Taking into account the above tasks, let us dwell on the approved experiments to study the regularities of chemical reactions, which are supposed to be carried out in chemistry programs of higher, specialized secondary and general secondary education.

\section{MAIN PART}

In general secondary and higher educational institutions of great theoretical and practical importance is the formation of knowledge and skills on the rate of chemical reaction and its definition, as well as the influence of various factors on the rate of reaction [2; p.35].

The more students know about the rate of chemical reactions, the easier it is for them to understand the nature and mechanism of chemical reactions. In the process of observing chemical experiments, they learn that the rate of reactions changes, as well as important factors affecting the reaction (temperature, pressure, concentration of reagents and catalyst) [4; p. 36].

It should be noted that in the program of the course of general and inorganic chemistry, a special place is given to the knowledge of the rate of chemical reactions. There are experiments on the dependence of the rate of chemical reactions on various factors and their detection, but there are few guidelines. In most cases, teachers will simply list the factors that increase the rate of chemical reactions.

In the experiments we recommend, students will see that the reaction rate depends on temperature, the presence of a catalyst, and the surface area of solids. Substances and catalysts, such as bertol salt, potassium permanganate, metallic zinc, marble, hydrochloric acid, are obtained in optimal quantities for the reaction, the reaction conditions are measured, and the experimental results are formulated.

Theoretical and practical teaching of the topic "The rate of chemical reactions and factors affecting it" is considered on the example of the course "General chemistry" in the bachelor's program "Chemistry" of pedagogical universities of the Republic of Uzbekistan and the subject "Chemistry" in secondary schools. At the same time, on an analytical basis, the volume of hours in the curriculum of the subject, the content of the topic in textbooks and teaching aids were studied. 
The American Journal of Applied sciences

(ISSN - 2689-0992)

Published: April 22, 2021 | Pages: 27-31

According to the chemistry program of the 8th grade of a comprehensive school on the topic "The rate of chemical reactions and the influence of various factors on it", only 1 hour is given. There are no separate hours allocated for laboratory experiments on this topic. In the modern era, when the formation of practical competencies in students is one of the urgent tasks of modern chemistry education, there is a need to improve practices.

In higher educational institutions, 4 hours of theoretical and 4 hours of laboratory studies are allocated for a bachelor's degree in Chemistry. The lack of the necessary reagents and equipment in universities requires quick and effective experiments in the practical study of the reaction rate and the factors affecting it. Accordingly, we aimed to build and test an improved experimental device in order to study the reaction rate and the factors influencing it.

Grades 8A and 8B of secondary school №16 of Uchkuprik district were chosen as the object of the experiment. Initially, the knowledge and practical skills of students in this class regarding the rate of a chemical reaction and the factors influencing it were monitored on the basis of oral questioning. According to the results, the quality of assimilation and knowledge of students on the topic did not correspond to the high indicators we expected. To ensure the reliability of the results of the experiments, the classes were divided into experimental and control classes.

Class 8A was designated as an experimental class and class 8B was designated as a control group. In the experimental class, the improved experimental setup developed by us was used only for experiments on the effect of catalyst and temperature on the reaction rate. In the control group, the experiments were carried out on the basis of a device consisting of devices given in the laboratory instructions for this subject.

On the basis of experiments carried out in both grades, students' practical knowledge and skills on the topic were retested in order to compare quality indicators. The analysis showed that the quality of assimilation and knowledge on the chosen topic in the experimental class changed significantly in comparison with the control class. The university carried out a comprehensive study of such factors as the effect of the catalyst and temperature on the reaction rate, the surface area of the reagents and the concentration of substances on the basis of an improved device. As the object of the pedagogical experiment, 101 and 102 groups of bachelor's degree "Chemistry" of the Faculty of Natural Sciences of the Kokand State Pedagogical Institute were selected. Group 101 was designated as experimental and group 102 as control.

The pedagogical experiments were organized as follows. In the experimental group, the effectiveness of the tool "Study of the action of important factors affecting a chemical reaction (catalyst, temperature, concentration of reagents and surface of a substance)" was investigated.

2 conical flasks with a volume of $500 \mathrm{ml}\left(\mathrm{a}, \mathrm{a}^{\prime}\right)$ and round tubes with a volume of $100 \mathrm{ml}\left(\mathrm{b}, \mathrm{b}^{\prime}\right)$, 2 graduated glass tubes with a volume of $25 \mathrm{ml}$ (c, c'), 2 lamps ( $\left.d, d^{\prime}\right)$ the device is assembled for the study of the electrical conductivity of solutions. 
The American Journal of Applied sciences

(ISSN - 2689-0992)

Published: April 22, 2021 | Pages: 27-31

\section{A. Effect of catalyst and temperature on reaction rate}

The dependence of the reaction rate on various factors was studied in parallel experiments. The effect of the catalyst and temperature on the reaction rate was studied by oxygen extraction methods. In this experiment, the reaction rate is determined by the volume of the new substance (oxygen) formed.

This is due to the fact that solids $\left(\mathrm{MnO}_{2}, \mathrm{KCl}\right)$ remain after the reaction instead of the bertol salt. To do this, add the same amount of 0.73 grams of berthollet salt to the flasks (b, b') of the device. $0.8 \mathrm{~g}$ of $\mathrm{MnO}_{2}$ catalyst was added to $b$. The flasks were heated in one flame and the results were as follows:

1. The d' lamp is on 1 minute after the start of heating (it is known that b' catalyst has been added to the lamp).

2. Light $d$ came on after 6 minutes (tube $b$ was without catalyst).

3. Both reactions produce the same amount of oxygen $(200 \mathrm{ml})$.

The rate of reaction in the presence of a catalyst.

$\mathrm{V}=\mathrm{v} / \mathrm{t}=200 \mathrm{ml} / 1 \mathrm{~min}=200 \mathrm{ml} / \mathrm{min}$

Reaction rate without catalyst,

$\mathrm{V}=\mathrm{v} / \mathrm{t}=200 \mathrm{ml} / 6 \mathrm{~min}=33.3 \mathrm{ml} / \mathrm{min}$

By comparing the rates of these two reactions, students find that the rate of the reaction is increased by a factor of 6 in the presence of a catalyst. In the same order, instead of the bertole salt, potassium permanganate $\left(\mathrm{KMnO}_{4}\right)$ is taken and placed in the same amount (b, b') in flasks, and flask b is heated in b flame stronger than b' bubble. Heating begins at the same time. Students will see the light bulb illuminate 2 minutes earlier than the light bulb and will conclude that the rate of decomposition increases with temperature.

\section{B. Dependence of the reaction rate on the size of the surface of the reagents.}

The dependence of the reaction rate on the surface area of the reagents was investigated as follows. The same amount of $3 \% \mathrm{HCl}$ solution was poured into the tubes of the device (b, b'), the same amount of granular zinc metal was added to flask $b$ ' and the same amount of powdered zinc metal ( $0.49 \mathrm{~g})$. Into flask b at the same time. In this case, due to the large surface area of zinc in tube $b$, the hydrogen in this tube is released so quickly that lamp $d$ is lit 1.5 minutes before the dlamp. After the experiment, the students came to the conclusion that the larger the surface area of a solid, the higher the reaction rate in which this substance is involved.

\section{Dependence of the reaction rate on the concentration of the substance}

The concentration of the reactants, part a, b, c of the apparatus shown in Figure 1 was used and the following experiment was performed.

Pour $\mathrm{HCl}$ solution (1: 1) into tube $b$ of the instrument, add 3 pieces of marble, $0.9 \mathrm{~g}$ each, and record the volume of gas generated every minute and get the following result.

$60 \mathrm{ml} \mathrm{CO} 2$ per minute. $56 \mathrm{ml}$ of $\mathrm{CO}_{2}$ was formed in 2 minutes. In 3 minutes, $40 \mathrm{ml}$ of $\mathrm{CO}_{2}$ was formed. In 4 minutes, $30 \mathrm{ml}$ of $\mathrm{CO}_{2}$ was formed. In 5 minutes, $14 \mathrm{ml}$ of $\mathrm{CO}_{2}$ was formed. From this result, the students saw that the amount 
of gas emitted decreased over time as the concentration of substances decreased.

They then concluded that there is a quantitative relationship between the reaction rate and the concentration of the reactants. The decrease in the reaction rate was explained by the dependence on the surface and the amount of marble that reacts. Based on the data obtained in this experiment, the relative reaction rates per minute were determined as follows: 60: 56: 40: 30: 14 or expressed as 4.3: 4.2: 2.8: 2.1: 1 , showed that the reaction rate in 1 minute was 4.3 times faster than the reaction rate in 5 minutes, and the reaction rate in 2 minutes was 4 times faster than in 5 minutes.

In the experimental group, students' practical skills on the topic "Reaction rate and factors affecting it" were controlled by oral questioning, which showed that the assimilation of the topic by students and the quality of knowledge significantly increased in comparison with the control group. In conclusion, it should be noted that the study of the rate of chemical reactions and the factors affecting them in general secondary schools and higher educational institutions in order to ensure the continuity and continuity of teaching seems to be one of the problems of improving the quality and efficiency of chemistry education.

\section{REFERENCES}

1. Нишонов М., Тешабоев С. Мактабда кимёдан амалий ишлар. - Т.: Ўқитувчи, 1992. - 1346.

2. Абдуллаев Г. Анорганик кимёдан амалий ишлар. - Т.: Мехнат, 1988. - 159 б.
3. Irgasheva G.A., Sirliboyev T.S. Anorganik kimyodan laboratoriya va mustaqil ish mashg ulotlari. 2005. - 1146.

4. Jumanov A.M. Kimyo fanidan laboratoriya mashg ulotlari. 2019. - 132 b. 